\title{
An Existence Result for Impulsive Stochastic Functional Differential Equations with Multiple Delays
}

\section{Anguraj $A^{*}$ and Banupriya $K$}

P.S.G. College of Arts and Science, Coimbatore, Tamil Nadu, India

\begin{abstract}
In this paper we consider Impulsive stochastic neutral functional differential equations with multiple delays. By using Schaefer's fixed point theorem, we prove the existence of solutions for stochastic differential equations with impulses.
\end{abstract}

Keywords: Impulsive differential equations; Stochastic differential equations; Multiple delay; Fixed point theorem

AMS Mathematical Subject Classification: 34A37, 34K50, 34K45, $60 \mathrm{H} 10$.

\section{Introduction}

The theory of impulsive differential equations is an important area of scientific activity. Many evolution processes are characterized by the fact that at certain moments of time they experience a change of state abruptly. These short term perturbations act instantaneously, that is in the form of impulses. For example, that many biological phenomena involving thresholds, optimal control models in economics and frequency modulated systems, do exhibit impulsive effects. So the impulsive differential equations appear as a natural description of observed evolution phenomena of several real world problems. Existence of solutions of impulsive differential equations has been studied by many authors. If the impulses are random the solution becomes a stochastic process. Existence of solutions of differential equations with random impulses have been studied by many authors [1-3].

Furthermore, besides impulsive effects, stochastic effects likewise exist in real systems. There is a wide range of interesting process in robotics, economics and biology that can be described as differential equations with non-deterministic dynamics such phenomena are described by stochastic differential equations. The solution of stochastic differential equation is a stochastic process. However the solution of differential equation with random impulses is different from the solution of stochastic differential equations. Existence, Uniqueness and qualitative analysis of solutions of stochastic differential equations have discussed by several authors $[4,5]$.

Since both impulsive and stochastic effects exist it is very difficult to investigate the existence of solution of impulsive stochastic differential equations. In [6] Anguraj and Vinodkumar discussed the existence, uniqueness and stability of impulsive stochastic semi linear neutral functional differential with infinite delays. Lakrib [7] discussed about the existence results for impulsive neutral functional differential equations with multiple delays. Based on the existing literature, stochastic impulsive differential equations involved mainly on controlability and stability. To the best of our knowledge, there is no work reported on impulsive stochastic differential equations with multiple delays. The purpose of this paper is to discuss about the existence results of impulsive stochastic neutral functional differential equations with multiple delays. Our approach is based on Schaefer's fixed point theorem.

In this paper we study the existence results for stochastic impulsive differential equations with multiple delays

$$
\begin{aligned}
& d\left[x(t)-f\left(t, x_{t}\right)\right]=\left[g\left(t, x_{t}\right)+\sum_{i=1}^{p} x\left(t-\tau_{i}\right)\right] d t+a\left(t, x_{t}\right) d B_{t} \\
& \text { a.e., } t \in J=[0,1], t \neq t_{k}, k=1,2, \ldots m . \\
& \Delta_{\mathrm{x}}\left(\mathrm{t}_{\mathrm{k}}\right)=\mathrm{I}_{\mathrm{k}}\left(\mathrm{x}\left(\mathrm{t}_{\mathrm{k}}\right)\right), \mathrm{k}=1,2, \ldots \mathrm{m} \\
& \mathrm{x}_{0}=\varphi
\end{aligned}
$$

where $\mathrm{f}: \mathrm{J} \times \mathrm{R}^{\mathrm{n}} \rightarrow \mathrm{R}^{\mathrm{n}}, \mathrm{g}: \mathrm{J} \times \mathrm{R}^{\mathrm{n}} \rightarrow \mathrm{R}^{\mathrm{n}}$ and $\mathrm{a}: \mathrm{J} \times \mathrm{R}^{\mathrm{n}} \rightarrow \mathrm{R}^{\mathrm{n}}$ are Borel Measurable functions, $J_{0}=[-r, 0], r=\max \{\tau i: i=1,2, \ldots p\}$ and $\varphi:[-r$, $0] \rightarrow \mathrm{R}_{\mathrm{n}}$. Further-more the fixed moments of time $\mathrm{t}_{\mathrm{k}}$ satisfy $0=\mathrm{t}_{0}<\mathrm{t}_{1}<\ldots$. $<\mathrm{t}_{\mathrm{m}}<\mathrm{t}_{\mathrm{m}+1}=1$, where $x\left(t_{k}^{+}\right)$and $x\left(t_{k}^{-}\right)$represent the right and left limits of $\mathrm{x}(\mathrm{t})$ at $\mathrm{t}=\mathrm{t}_{\mathrm{k}}$, respectively. And $\Delta x\left(t=t_{k}\right)=x\left(t_{k}^{+}\right)-x\left(t_{k}^{-}\right), k=1,2, \ldots . m$ represent the jump in the state at time $t_{k}$ with $I_{k}$ determining the size of the jump.

\section{Preliminaries}

Let $\left(\bar{\Omega}, \mathrm{F}\left\{F_{t}\right\}_{t \geq 0}, P\right)$ be a complete probability space with a filtration $\{\mathrm{Ft}\}_{\mathrm{t} \geq 0}$ satisfying the conditions that it is right continuous and $\mathrm{F}_{0}$ contains all $\mathrm{P}$ - null sets and $\mathrm{w}(\mathrm{t})=\left(\mathrm{w}_{1}(\mathrm{t}), \ldots . \mathrm{w}_{\mathrm{m}}(\mathrm{t})\right)^{\mathrm{T}}$ is an $\mathrm{m}$-dimensional Brownian motion defined on $\left(\bar{\Omega}, \mathrm{F}\left\{F_{t}\right\}_{t \geq 0}, P\right)$. Let $\mathrm{C}=\mathrm{C}\left[[-\mathrm{r}, 0], \mathrm{R}^{\mathrm{n}}\right]$ denote the family of all continuous $\mathrm{R}_{\mathrm{n}}$-valued function $\varphi$ on $[-\mathrm{r}, 0]$ with the norm $\|\phi\|=\sup _{-r \leq \theta \leq 0}|\phi(\theta)|$ where $|$.$| is Euclidean norm of \mathrm{R}_{\mathrm{n}}$. Denote by $C_{F_{0}}^{b}\left[[-r, 0], R^{n}\right]$ the family of all bounded F0- measurable, $C\left[[-r, 0], R^{n}\right]$ -valued random variables $\varphi$, satisfying $\|\phi\|_{L^{2}}^{2}=\sup _{-r \leq \theta \leq 0} E|\phi(\theta)|^{2}<\infty$, where $\mathrm{E}$ denotes the expectation of stochastic process [8-10]. The initial condition $\phi \in C_{F_{0}}^{b}\left[[-r, 0], R^{n}\right]$.

Let $\mathrm{PC}\left(\mathrm{J}, \mathrm{R}^{\mathrm{n}}\right)$ the space of piecewise continuous functions $\mathrm{x}: \mathrm{J} \rightarrow \mathrm{R}^{\mathrm{n}}$ such that $\mathrm{x}$ is continuous everywhere except for $\mathrm{t}=\mathrm{t}_{\mathrm{k}}$ at which $x\left(t_{k}^{-}\right)$ and $x\left(t_{k}^{+}\right)$exist and $x\left(t_{k}^{-}\right)=x\left(t_{k}\right), k=1, \ldots m$. If we set $\Omega=\left\{\mathrm{x}: \mathrm{J}_{1} \rightarrow \mathrm{R}^{\mathrm{n}}, \mathrm{x} \in\right.$ $\left.\mathrm{R}^{\mathrm{n}} \cap \mathrm{PC}\left(\mathrm{J}, \mathrm{R}^{\mathrm{n}}\right)\right\}$ where $\mathrm{J}_{1}=[-\mathrm{r}, 1]$ then $\Omega$ is a Banach space normed by $\|x\|=\sup \left\{|x(t)|: t \in J_{1}\right\}, x \in \Omega$.

*Corresponding author: Anguraj A, P.S.G. College of Arts and Science Coimbatore-641 014, Tamil Nadu, India, Tel: 0422430 3300; E-mail: angurajpsg@yahoo.com

Received April 11, 2015; Accepted June 09, 2015; Published June 16, 2015

Citation: Anguraj A, Banupriya K (2015) An Existence Result for Impulsive Stochastic Functional Differential Equations with Multiple Delays. J Phys Math 6: 139. doi:10.4172/2090-0902.1000139

Copyright: $\odot 2015$ Anguraj $A$, et al. This is an open-access article distributed under the terms of the Creative Commons Attribution License, which permits unrestricted use, distribution, and reproduction in any medium, provided the original author and source are credited. 
Obviously, for any $\mathrm{x} \in \Omega$ and $\mathrm{t} \in \mathrm{J}$, the function $\mathrm{x}_{\mathrm{t}}$ defined by $x_{t}(\theta)=x(t+\theta)$, for $\theta \in J_{0}$, belongs to $R_{n}$.

By $L^{1}\left(J, R^{n}\right)$ we denote the Banach space of measurable functions $\mathrm{x}$ : $\mathrm{J} \rightarrow \mathrm{R}^{\mathrm{n}}$ which are Lebesgue integrable, normed by

$$
\|x\|=\int_{0}^{1} x(t) d t
$$

Definition 2.1: A stochastic process $\left\{x(t) \in C_{F_{0}}^{b}\left[[-r, 0], R^{n}\right], t \in[-r, 1]\right\}$, is called a solution of equations (1.1) if

(i) $\mathrm{x}(\mathrm{t})$ is $\mathrm{F}_{\mathrm{t}}$ adapted;

(ii) $\mathrm{x}(\mathrm{t})$ satisfies the integral equation

$$
x(t)=\left\{\begin{array}{l}
\phi(t) \quad \text { for } t \in J_{0}, \\
\phi(0)-f(0, \phi(0))+f\left(t, x_{t}\right)+\int_{0}^{t} g\left(s, x_{s}\right) d s+\sum_{i=1}^{p} \int_{-\tau_{i}}^{0} \phi(s) d s \\
+\sum_{i=1}^{p} \int_{0}^{t-\tau_{i}} x(s) d s+\int_{0}^{t} a\left(s, x_{s}\right) d B(s)+\sum_{0<t_{k}<t} I_{k}\left(x\left(t_{k}^{-}\right)\right) \quad \text { for } t \in J
\end{array}\right.
$$

Definition 2.2: (Schaefer fixed point theorem). Let $\mathrm{X}$ be a normed linear space and let $\Gamma: \mathrm{X} \rightarrow \mathrm{X}$ be a completely continuous map, that is, it is a continuous mapping which is compact on each bounded subset of $X$. If the set $\zeta=\{x \in \in X: \lambda x=\Gamma x$ for some $\lambda>1\}$ is bounded, then $\Gamma$ has a fixed point [11].

\section{Hypotheses}

$\mathrm{H}_{1}$ : The function $\mathrm{f}, \mathrm{g}: \mathrm{J} \times \mathrm{R}^{\mathrm{n}} \rightarrow \mathrm{R}^{\mathrm{n}}$ is such that

$$
\| f\left(t, x_{t}\left\|^{2} \vee\right\| g\left(t, x_{t}\left\|^{2} \leq c_{1}\right\| x_{t} \|^{2}+c_{2}\right.\right.
$$

for each $t \in[0,1]$ and $c 1, c 2>0$ are constants.

$\mathrm{H}_{2}$ : The function a: $\mathrm{J} \times \mathrm{R}^{\mathrm{n}} \rightarrow \mathrm{R}^{\mathrm{n}}$ is Caratheodory, that is,

(i) $t \mapsto a(t, x)$ is measurable for each $\mathrm{x} \in \mathrm{R}$,

(ii) $x \mapsto a(t, x)$ is continuous for a.e $\mathrm{t} \in \mathrm{J}$.

H3: There exists a function $q \in L^{1}\left(J, R^{n}\right)$ with $q(t)>0$ for a.e $t \in J$ and a continuous non decreasing function $\psi:[0, \infty) \rightarrow[0, \infty)$ such that

$$
|a(t, x)| \leq q(t) \psi(\|x\|)
$$

for a.e $\mathrm{t} \in \mathrm{J}$ and each $\mathrm{x} \in \mathrm{R}^{\mathrm{n}}$ with

$$
\int_{C}^{\infty} \frac{d s}{s+\psi(s)}=\infty
$$

Where

$$
C=\frac{1}{1-2 c_{1}}\left[\|\phi\|\left(1+c_{1}+\sum_{i=1}^{p} \tau_{i}\right)+3 c_{2}\right]
$$

$\mathrm{H}_{4}$ : The function $\mathrm{I}_{\mathrm{k}}: \mathrm{R} \rightarrow \mathrm{R}$ and there exist positive constant $\mathrm{c}_{\mathrm{k}}, \mathrm{k}=1$, $2, \ldots . \mathrm{m}$, such that $\left\|I_{k}(x)\right\| \leq c_{k}, x \in R$

Theorem 2.1: Suppose that the conditions $\left(\mathrm{H}_{1}\right)-\left(\mathrm{H}_{4}\right)$ are satisfied then there exists a solution of the problem (1.1) on J [12-14].

Proof: Transform the problem (1.1) - (1.3) into a fixed point problem. Consider the operator $\Gamma: \Omega \rightarrow \Omega$ defined by

$$
\Gamma(x(t))=\left\{\begin{array}{l}
\phi(t) \text { for } t \in J_{0}, \\
\phi(0)-f(0, \phi(0))+f\left(t, x_{t}\right)+\int_{0}^{t} g\left(s, x_{s}\right) d s+\sum_{i=1}^{p} \int_{-\tau_{i}}^{0} \phi(s) d s \\
+\sum_{i=1}^{p} \int_{0}^{t-\tau_{i}} x(s) d s+\int_{0}^{t} a\left(s, x_{s}\right) d B(s)+\sum_{0<t_{k}<t} I_{k}\left(x\left(t_{k}^{-}\right)\right) \text {for } t \in J
\end{array}\right.
$$

Step 1: $\Gamma$ has bounded values for bounded sets in $\Omega$.

Let B be a bounded set in $\Omega$. Then there exists a real number $\rho>0$ such that $E\|x\|^{2} \leq \rho$, for all $\mathrm{x} \in \mathrm{B}$.

Let $\mathrm{x} \in \mathrm{B}$ and $\mathrm{t} \in \mathrm{J}$, we have

$$
\begin{aligned}
& \Gamma x(t)=\phi(0)-f(0, \phi(0))+f\left(t, x_{t}\right)+\int_{0}^{t} g\left(s, x_{s}\right) d s+\sum_{i=1}^{p} \int_{-\tau_{i}}^{0} \phi(s) d s \\
& +\sum_{i=1}^{p} \int_{0}^{t-\tau_{i}} x(s) d s+\int_{0}^{t} a\left(s, x_{s}\right) d B(s)+\sum_{0<t_{k} I_{k}} I_{k}\left(x\left(t_{k}^{-}\right)\right) \\
& E\|\Gamma x(t)\|^{2} \leq E\|\phi\|^{2}+c_{1} E\|\phi\|^{2}+c_{2}+c_{1} E\left\|x_{t}\right\|^{2}+c_{2}+E \int_{0}^{1}\left\|g\left(s, x_{s}\right)\right\|^{2} d s+\sum_{i=1}^{p} \tau_{i} E\|\phi\|^{2} \\
& +p\left(E\left\|x_{t}\right\|^{2}\right)+E \int_{0}^{1}\left\|a\left(s, x_{s}\right)\right\|^{2} d s+\sum_{0 t_{k}<t} E I_{k}\left(x\left(t_{k}^{-}\right)\right) \\
& \leq E\|\phi\|^{2}\left(1+c_{1}+\sum_{i=1}^{p} \tau_{i}\right)+2 c_{2}+\left(c_{1}+p\right) E\left\|x_{t}\right\|^{2}+\int_{0}^{1}\left(c_{1} E\left\|x_{s}\right\|^{2}+c_{2}\right) d s \\
& +\int_{0}^{1} q(s) \psi\left(E\left\|x_{s}\right\|^{2}\right) d s+m \sum_{0<t_{k}<t} c_{k}^{2} \\
& \leq\|\phi\|^{2}\left(1+c_{1}+\sum_{i=1}^{p} \tau_{i}\right)+2 c_{2}+\left(c_{1}+p\right) \rho+\left(c_{1} \rho+c_{2}\right)+\psi(\rho) \int_{0}^{1} q(s) d s \\
& +m \sum_{0<t_{k}<t} c_{k}^{2} \\
& \leq E\|\phi\|^{2}\left(1+c_{1}+\sum_{i=1}^{p} \tau_{i}\right)+3 c_{2}+2 c_{1} \rho+p \rho+\psi(\rho)\|q\|+m \sum_{0<t_{k}<t} c_{k}^{2} \\
& \leq \eta(s a y)
\end{aligned}
$$

If $\mathrm{t} \in \mathrm{J}_{0}$, then $E\|\Gamma x\|^{2} \leq\|\phi\|^{2}$ and hence $E\|\Gamma x\|^{2} \leq \eta$ for all $\mathrm{x} \in \mathrm{B}$, that is $\Gamma$ is bounded on bounded subsets of $\Omega$.

Step 2: $\Gamma$ maps bounded sets into equicontinuous sets.

Let $\mathrm{B}$ be as in Step 1 and $\mathrm{x} \in \mathrm{B}$. Let $\mathrm{t}$ and $h \neq 0$ be such that $\mathrm{t}, \mathrm{t}+$ $\mathrm{h} \in J \backslash\left\{\mathrm{t}_{1}, \mathrm{t}_{2}, \ldots . \mathrm{t}_{\mathrm{m}}\right\}$

Now

$$
\begin{aligned}
& E\|\Gamma x(t+h)-\Gamma x(t)\|^{2} \leq E\left\|f\left(t+h, x_{t+h}\right)-f\left(t, x_{t}\right)\right\|^{2}+E \int_{t}^{(t+h)}\left\|g\left(s, x_{s}\right)\right\|^{2} d s \\
& +p h E\|x\|^{2}+E \int_{t}^{(t+h)}\left\|a\left(s, x_{s}\right)\right\|^{2} d s+\sum_{t<t_{k}<t+h} E\left\|I_{k}\left(x\left(t_{k}^{-}\right)\right)\right\|^{2} \\
& \leq E\left\|f\left(t+h, x_{t+h}\right)-f\left(t, x_{t}\right)\right\|^{2}+E \int_{t}^{(t+h)}\left\|g\left(s, x_{s}\right)\right\|^{2} d s \\
& +p h \rho+E \int_{t}^{(t+h)}\left\|a\left(s, x_{s}\right)\right\|^{2} d s+\sum_{t t_{k}<t+h} E\left\|I_{k}\left(x\left(t_{k}^{-}\right)\right)\right\|^{2}
\end{aligned}
$$

as $h \rightarrow 0$, the right hand side of the above inequality tends to zero. This implies the equicontinuity on $J \backslash\left\{\mathrm{t}_{1}, \mathrm{t}_{2}, \ldots . \mathrm{t}_{\mathrm{m}}\right\}$.

It remains to examine at $\mathrm{t}=\mathrm{t}_{\mathrm{i}}, \mathrm{i}=1,2, \ldots . \mathrm{m}$. Let $h \neq 0$ be such that $\left\{t_{k}: k \neq i\right\} \cap\left[t_{i}-|h|, t_{i}-|h|\right]=\varnothing$ Thus we have

$$
\left\|\Gamma x\left(t_{i}+h\right)-\Gamma x\left(t_{i}\right)\right\| \leq E \| f\left(t+h, x_{t+h}-f\left(t, x_{t}\right) \|^{2}\right.
$$




$$
+E \int_{t_{i}}^{t_{i}+h}\left(c_{1}\left\|x_{s}\right\|^{2}+c_{2}\right) d s+p \rho h+\psi(\rho) \int_{t_{i}}^{t_{i}+h} q(s) d s
$$

The right hand side of the above inequality tends to zero as $\mathrm{h} \rightarrow 0$. The equicontinuity on $\mathrm{J}_{0}$ follows from the uniform continuity of $\varphi$ on this interval.

\section{Step 3: Now we show that $\Gamma$ is continuous}

Let $\left\{\mathrm{x}_{\mathrm{n}}\right\} \subset \Omega$ be a sequence such that $\mathrm{x}_{\mathrm{n}} \rightarrow \mathrm{x}$. We will show that $\Gamma \mathrm{x}_{\mathrm{n}}$ $\rightarrow \Gamma \mathrm{x}$.

For $\mathrm{t} \in \mathrm{J}$

$$
\begin{aligned}
& E\left\|\Gamma x_{n}-\Gamma x\right\|^{2}=E \| f\left(t, x_{n t}\right)-f\left(t, x_{t}\right)+\int_{0}^{1}\left(g\left(s, x_{n s}\right)-g\left(s, x_{s}\right)\right) d s+p \int_{0}^{1}\left(x_{n}(s)-x(s)\right) d s \\
& +\int_{0}^{1}\left(a\left(s, x_{n}\right)-a(s, x)\right) d B(s)+\sum_{k=1}^{m}\left(I_{k}\left(x_{n}\left(t_{k}^{-}\right)\right)-I_{k}\left(x\left(t_{k}^{-}\right)\right)\right. \\
& \leq 3 E\left\|f\left(t, x_{n t}\right)-f\left(t, x_{t}\right)\right\|^{2}+3 E \int_{0}^{1}\left\|\left(g\left(s, x_{n s}\right)-g\left(s, x_{s}\right)\right)\right\|^{2} d s \\
& +3 p E \int_{0}^{1}\left\|x_{n}(s)-x(s)\right\|^{2} d s+3 E \int_{0}^{1}\left\|\left(a\left(s, x_{n}\right)-a(s, x)\right)\right\|^{2} d s \\
& +3 m \sum_{k=1}^{m} E \|\left(I_{k}\left(x_{n}\left(t_{k}^{-}\right)\right)-I_{k}\left(x\left(t_{k}^{-}\right)\right) \|^{2}(3.2)\right.
\end{aligned}
$$

Using $\mathrm{H}_{3}$ it can be easily shown that the function $t \mapsto g\left(t, x_{n t}\right)-g\left(t, x_{t}\right)$ is Lebesgue integrable. By the continuity of $\mathrm{f}$ and $\mathrm{I}_{\mathrm{k}}, \mathrm{k}=1,2, \ldots \mathrm{m}$ and the dominated convergence theorem, the right hand side of inequality (3.2) tends to zero as $n \rightarrow \infty$, which completes the proof that $\Gamma$ is continuous [15-18].

As a sequence of steps 1 to 3, together with the Arzela-Ascoli theorem, we conclude that $\Gamma$ is completely continuous.

To complete the proof of the theorem, it suffices to prove the following step.

\section{Step 4:}

There exists a priori bound of the set

$\varsigma=\{\mathrm{x} \in \Omega: \lambda \mathrm{x}=\Gamma \mathrm{x}$ for some $\lambda>1\}$

Let $x \in \varsigma$ and $\lambda>1$ be such that $\lambda x=\Gamma x$. Then $x \mid\left[-r, t_{1}\right]$ satisfies for each $\mathrm{t} \in\left[0, \mathrm{t}_{1}\right]$,

$$
\begin{aligned}
& x(t)=\lambda^{-1}\left[\phi(0)-f(0, \phi(0))+f\left(t, x_{t}\right)+\int_{0}^{t} g\left(s, x_{s}\right) d s+\int_{0}^{t} a\left(s, x_{s}\right) d B(s)\right. \\
& \left.+\sum_{i=1}^{p} \int_{-\tau_{i}}^{0} \phi(s) d s+\sum_{i=1}^{p} \int_{0}^{t-\tau_{i}} x(s) d s\right]
\end{aligned}
$$

It is easy to verify that

$$
\begin{aligned}
& E\|x(t)\|^{2} \leq E\|\phi\|^{2}\left(1+c_{1}+\sum_{i=1}^{p} \tau_{i}\right)+2 c_{1}\left\|x_{t}\right\|^{2} \\
& \left.+3 c_{2}+\int_{0}^{t}\left(q(s) \psi\left(E\left\|x_{s}\right\|^{2}\right)+p E\left\|x_{s}\right\|^{2}\right)\right) d s
\end{aligned}
$$

Consider the function $\mathrm{v}_{1}(\mathrm{t})=\sup \left\{E\|x(s)\|^{2}: s \in[-r, t]\right\}$, for $\mathrm{t} \in\left[0, \mathrm{t}_{1}\right]$. We have $\left\|x_{t}\right\|^{2} \leq v_{1}(t)$ for all $\mathrm{t} \in\left[0, \mathrm{t}_{1}\right]$ and there is a point $\mathrm{t}^{*} \in[-\mathrm{r}, \mathrm{t}]$ such that $v_{1}(t)=\left\|x_{t}^{*}\right\|^{2}$ If $\mathrm{t}^{*}<0$, we have $v_{1}(t) \leq\|\phi\|^{2}$ for all $\mathrm{t} \in\left[0, \mathrm{t}_{1}\right]$. Now, if $\mathrm{t}^{*}$ $\geq 0$ from (3.3) it follows that,

for $\mathrm{t} \in\left[0, \mathrm{t}_{1}\right]$,

$v_{1}(t) \leq E\|\phi\|^{2}\left(1+c_{1}+\sum_{i=1}^{p} \tau_{i}\right)+2 c_{1} v_{1}(t)+3 c_{2}+\int_{0}^{t}\left(q(s) \psi\left(v_{1}(s)\right)+p v_{1}(s)\right) d s$

And hence

$v_{1}(t) \leq C_{1}^{1}+C_{1}^{2} \int_{0}^{t} Q(s)\left[\psi\left(v_{1}(s)\right)+v_{1}(s)\right] d s$
Where

$$
\begin{aligned}
& C_{1}^{1}=C_{1}^{2}\left[\|\phi\|^{2}\left(1+c_{1}+\sum_{i=1}^{p} \tau_{i}\right)+3 c_{2}\right] \\
& C_{1}^{2}=\frac{1}{1-2 c_{1}} \text { And } \mathrm{Q}(\mathrm{t})=\max \{\mathrm{q}(\mathrm{t}), \mathrm{p}\}, \text { for } \mathrm{t} \in\left[0, \mathrm{t}_{1}\right]
\end{aligned}
$$

Set,

$w_{1}(t)=C_{1}^{1}+C_{1}^{2} \int_{0}^{t} Q(s)\left[\psi\left(v_{1}(s)\right)+v_{1}(s)\right] d s$ for $t \in\left[0, t_{1}\right]$

Then we have $v_{1}(t) \leq w_{1}(t)$ for all $t \in\left[0, t_{1}\right]$

A direct differentiation of $\mathrm{w}_{1}$ yields

$$
\left\{\begin{array}{l}
\left.w_{1}{ }^{\prime}(t) \leq Q(t)\left[\psi\left(w_{1}(t)\right)+w_{1}(t)\right)\right], \text { a.e, } t \in\left[0, t_{1}\right] \\
w_{1}(0)=C_{1}^{(1)}
\end{array}\right.
$$

By integration, this gives

$$
\int_{0}^{t} \frac{w_{1^{\prime}}(s)}{\psi\left[\left(w_{1}(s)\right)+w_{1}(s)\right]} d s \leq \int_{0}^{t} Q(s) d s \leq\|Q\| \quad t \in\left[0, t_{1}\right]
$$

By a change of variables, inequality (3.4) becomes,

$\int_{C_{1}^{1}}^{w_{1}(t)} \frac{d s}{\psi(s)+s} \leq\|Q\|, \quad t \in\left[0, t_{1}\right]$

By (3.1) and the mean value theorem, there is a constant $\mathrm{M}_{1}=\mathrm{M}_{1}\left(\mathrm{t}_{1}\right)>0$ such that $\mathrm{w}_{1}(\mathrm{t}) \leq \mathrm{M}_{1}$ for all $\mathrm{t} \in\left[0, \mathrm{t}_{1}\right]$

That is $v_{1}(t) \leq M_{1}$ for all $t \in\left[0, t_{1}\right]$

At last we choose $\mathrm{M}_{1}$ such that $\|\phi\| \leq M_{1}$ to get

$\sup \left\{E\|x(t)\|^{2}: t \in\left[-r, t_{1}\right]\right\}=v_{1}\left(t_{1}\right) \leq M_{1}$

Now, consider $\left.x\right|_{\left[-r, t_{2}\right]}$, satisfies for each $\mathrm{t} \in\left[0, \mathrm{t}_{2}\right]$

$x(t)=\lambda^{-1}\left[\phi(0)-f(0, \phi(0))+f\left(t, x_{t}\right)+\int_{0}^{t} g\left(s, x_{s}\right) d s+\int_{0}^{t} a\left(s, x_{s}\right) d B(s)\right.$

$\left.+\sum_{i=1}^{p} \int_{-\tau_{i}}^{0} \phi(s) d s+\sum_{i=1}^{p} \int_{0}^{t-\tau_{i}} x(s) d s+I_{1}\left(x\left(t_{1}\right)\right)\right]$

$E\|x(t)\|^{2} \leq E\|\phi\|^{2}\left(1+c_{1}+\sum_{i=1}^{p} \tau_{i}\right)+2 c_{1}\left\|x_{t}\right\|^{2}+3 c_{2}$

$+\int_{0}^{t}\left[q(s) \psi\left(\left.E\|x\|\right|_{s} ^{2}+p E\|x\|_{s}^{2}\right] d s+\sup E\left\|I_{1}(u)\right\|^{2}:\|u\| \leq M_{1}\right.$

Denote $v_{2}(t)=\sup \left\{E\|x(s)\|^{2}: s \in[-r, t]\right\}$, for $\mathrm{t} \in\left[0, \mathrm{t}_{2}\right]$, Then for each $\mathrm{t}$ $\in\left[0, \mathrm{t}_{2}\right]$, we have $\|x(t)\|$, such that $\left\|x_{t}\right\|^{2} \leq v_{2}(t)$.

Let $\mathrm{t}^{*} \in[-\mathrm{r}, \mathrm{t}]$ be such that $v_{2}(t)=\left\|x\left(t^{*}\right)\right\|^{2}$.

If $\mathrm{t}^{*}<0$, we have $v_{2}(t) \leq\|\phi\|^{2}$ for all $\mathrm{t} \in\left[0, \mathrm{t}_{2}\right]$.

Now if $t^{*} \geq 0$, then by (3.5) we have for $t \in\left[0, t_{2}\right]$

$\mathrm{v}_{2}(\mathrm{t}) \leq E\|\phi\|^{2}\left(1+c_{1}+\sum_{i=1}^{p} \tau_{i}\right)+2 \mathrm{c}_{1} \mathrm{v}_{2}(\mathrm{t})+3 \mathrm{c}_{2}+\int_{0}^{t}\left[q(s) \psi\left(v_{2}(s)\right)+p v_{2}(s)\right]$

$+\sup \left\{E\left\|I_{1}(u)\right\|^{2}:\|u\| \leq M_{1}\right\}$

$\mathrm{v}_{2}(\mathrm{t}) \leq C_{2}^{1}+C_{2}^{2} \int_{0}^{t}\left[Q(s) \psi\left(v_{2}(s)\right)+p v_{2}(s)\right]$

Where

$C_{2}^{1} C_{2}^{2} E\|\phi\|^{2}\left(1+c_{1}+\sum_{i=1}^{p} \tau_{i}\right)+3 c_{2}+\sup E\left\|I_{1}(u)\right\|^{2}:\|u\| \leq M_{1}$ 
Citation: Anguraj A, Banupriya K (2015) An Existence Result for Impulsive Stochastic Functional Differential Equations with Multiple Delays. J Phys Math 6: 139. doi:10.4172/2090-0902.1000139

Page 4 of 4

$$
C_{2}^{2}=\frac{1}{1-2 c_{1}}
$$

And $Q(t)=\operatorname{Max}\{q(t), p\}$, for $t \in\left[0, t_{2}\right]$.

If we set,

$w_{2}(t)=C_{2}^{1}+C_{2}^{2} \int_{0}^{t} Q(s)\left[\psi\left(v_{2}(s)\right)+v_{2}(s)\right] d s$ for $t \in\left[0, t_{2}\right]$

Then we get $\mathrm{v}_{2}(\mathrm{t}) \leq \mathrm{w}_{2}(\mathrm{t})$ for all $\mathrm{t} \in\left[0, \mathrm{t}_{2}\right]$ and

$$
\left\{\begin{array}{l}
w_{2^{\prime}}(t) \leq Q(t)\left[\psi\left(w_{2}(t)\right)+w_{2}(t)\right] ., \text { a.e, } t \in\left[0, t_{2}\right] \\
w_{2}(0)=C_{2}^{1}
\end{array}\right.
$$

These yields,

$$
\begin{aligned}
& \int_{0}^{t} \frac{w_{2^{\prime}}(t)}{\psi\left(w_{2}(s)\right)+p w_{2}(s)} d s \leq \int_{0}^{t} Q(s) d s \leq\|Q\|, t \in\left[0, t_{2}\right] \\
& \int_{C_{2}^{1}}^{w_{2}(t)} \frac{d s}{\psi(s)+s} \leq\|Q\|, t \in\left[0, t_{2}\right]
\end{aligned}
$$

Again by (3.1) and the mean value theorem, there is a constant $M_{2}=M_{2}\left(t_{1}, t_{2}\right)>0$ such that $w_{2}(t) \leq M_{2}$ for all $t \in\left[0, t_{2}\right]$, and then $v_{2}(t) \leq$ $\mathrm{M}_{2}$ for all $\mathrm{t} \in\left[0, \mathrm{t}_{2}\right]$. Finally, if we

Choose $\mathrm{M}_{2}$ such that $\varphi \leq \mathrm{M}_{2}$, we get,

$$
\sup \left\{E\|x(t)\|^{2}: t \in\left[-r, t_{2}\right]\right\}=v_{2}\left(t_{2}\right) \leq M_{2}
$$

Continue this process for $\left.\mathrm{x}\right|_{[-\mathrm{r}, \mathrm{t}]}, \ldots . \mathrm{x} \mid \mathrm{J}_{1}$, we obtain that there exists a constant $\mathrm{M}=\mathrm{M}\left(\mathrm{t}_{1}, \ldots \mathrm{t}_{\mathrm{m}}\right)>0$ such that $\mathrm{x} \leq \mathrm{M}$.

This finish to show that the $\zeta$ is bounded in $\Omega$.

As a result the conclusion of theorem holds and consequently the problem (1.1) has a solution $\mathrm{x}$ on $\mathrm{J}_{1}$. This completes the proof [19].

\section{References}

1. Anguraj A, Shujin Wu, Vinodkumar A (2011) The existence and exponential stability of semilinear functional differential equations with random impulses under non-uniqueness. Nonlinear Analysis 74: 331-342.

2. Wu S (2007) The Euler scheme for random impulsive differential equations. Applied Mathematics and Computation 191: 164-175.

3. Wu SJ, Han D (2005) exponential stability of functional differential systems with impulsive effect on random moments. Computer and Mathematics with Applications 50: 321-328.
4. Ren Y, Xia N (2009) A note on the existence and uniqueness of the solution to neutral stochastic functional differential equations with infinite delay.applied mathematics and computation 214: 457-461.

5. Sakthivel R, Luo J (2009) asymptotic stability of nonlinear impulsive stochastic differential equations. Statistics and Probability Letters 9: 1219-1223.

6. Anguraj A, Vinodkumar A (2009) Existence, Uniqueness and stability Results of Impulsive Stochastic Semi linear Neutral Functional Differential Equations with Infinite delays. Electronic Journal of Qualitative Theory of Differential Equations 67: 1-13.

7. Lakrib M (2008) An existence result for impulsive neutral functional differentia equations with multiple delay. Electronic Journal of Differential equations 36: $1-7$

8. Oksendal B (2002) Stochastic Differential Equations An Introduction with Applications: $\left(5^{\text {th }} e d n\right)$, springer, Berlin, Germany.

9. Mao X (1997) stochastic differential equations and their Applications. Horwood Publishing, Chichester, UK.

10. Balachandran K, Kiruthika S (2010) Existence of solutions of Abstract fractional Impulsive Semi linear evolution Equations, Electronic. Journal of Qualitative Theory of Differential Equations 4: 1-12.

11. Sakthivel R, Luo J (2009) asymptotic stability of impulsive stochastic partial differential equations with infinite delays. J Math Anal Appl 356: 1-6.

12. Pan $L$ (2012) Existence of mild solution for impulsive stochastic differentia equations with non-local conditions. Differential Equations and Applications 4 485-494

13. Guendouzi T, Mehdi K (2013) existence of mild solutions for impulsive fractional stochastic equations with infinite delay. Malaya Journal of Mathematik 4: 30-43.

14. Anguraj A, Karthikeyan K (2009) Existence of solutions for impulsive neutra functional differential equations with nonlocal conditions. Nonlinear Anal 70 2717-2721.

15. Yang Z, Xu D, Xiang L (2006) Exponential p-stability of impulsive stochastic differential equations with delays. Physics Letters 359: 129-137.

16. Benchora M, Henderson J, Ntouyas SK (2006) Impulsive Differential equations and Inclusions. Hindawi Publishing Corporation, New York, USA.

17. Bao H, Cao J (2009) Existence and Uniqueness of solutions to neutral stochastic functional differential equations with infinite delay. Applied mathematics and Computation 215: 1732-1743.

18. Sakthivel R, Luo J (2009) asymptotic stability of nonlinear impulsive stochastic differential equations. Statistics and Probability Letters 9: 1219-1223.

19. Hernandez EM, Rabello M, Hernan R, Henriquez HR (2007) existence of solutions for impulsive partial neutral functional differential equations. J Math Anal Appl 331: 1135-1158.

Submit your next manuscript and get advantages of OMICS Group submissions

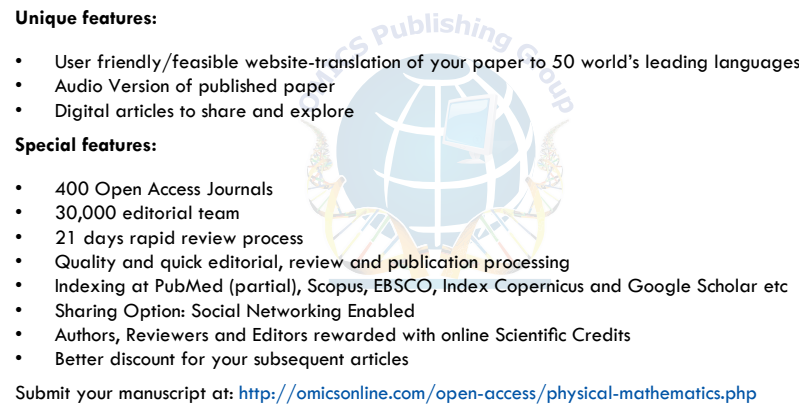

